\title{
Toddler with Isolated Motor Delay and Rickets
}

\author{
Prateek Kumar Panda ${ }^{1} \cdot$ Bhavna Chopra ${ }^{1} \cdot$ Indar Kumar Sharawat ${ }^{1}$
}

Received: 19 March 2020 / Accepted: 30 March 2020 / Published online: 17 April 2020

(C) Dr. K C Chaudhuri Foundation 2020

To the Editor: A one-and- a half-year-old boy presented with complaints of delayed walking. He was born to a nonconsanguineous couple with a normal perinatal period. He attained standing with support a few days before the presentation, however, was not able to walk independently. Language and social milestones were normal. His family history was non-contributory. On examination he had frontal bossing, open anterior fontanelle, Harrison sulcus, and bilateral wrist and ankle widening. Neurological examination showed mild hypotonia with preserved muscle stretch reflex. Radiographs of the bilateral wrist and ankle showed generalized osteopenia, and cupping, fraying and splaying of the metaphysis of long bones.

Investigations revealed normal serum calcium, phosphorus, elevated alkaline phosphatase levels (1357 U) and low vitamin D $(25-\mathrm{OH})$ levels $(10 \mathrm{ng} / \mathrm{ml})$. He was treated with oral Calcirol sachets as per the standard protocol. His repeat vitamin D level after one month was normal $(36.2 \mathrm{ng} / \mathrm{ml})$ and a repeat radiograph showed evidence of healing rickets. However, he continued to have hypotonia at 3 mo follow up and his motor milestones did not improve. He was re-examined, and his examination findings were similar except fixed flexion contracture of around 10-15 degrees in the bilateral elbow and mild distal hyperlaxity of fingers. Next-generation sequencing showed a heterozygous pathogenic variant $(\mathrm{c} .199 \mathrm{~A}>\mathrm{T})$ in the COL6A3 gene, which confirmed the diagnosis of Ullrich congenital muscular dystrophy.

Isolated motor delay may be seen in systemic disorders like protein-energy malnutrition, anemia, rickets, skeletal dysplasia, neurogenetic syndromes like Down syndrome, upper motor neuron pathology like spastic diplegic cerebral palsy, spinal cord pathology including neural tube defect and more commonly, in neuromuscular disorders like congenital myopathy, congenital muscular dystrophy and spinal muscular atrophy [1-3]. Although systemic causes like malnutrition, anemia and vitamin

Indar Kumar Sharawat

sherawatdrindar@gmail.com

1 Pediatric Neurology Division, Department of Pediatrics, All India Institute of Medical Sciences, Rishikesh, Uttarakhand, India
D deficiency [4] are widely prevalent in developing countries and appear to be the most predominant etiology for isolated motor delay at outset, often they are only minor contributing factors and the child may harbor another underlying pathology. Hence, physicians need to be vigilant during clinical examination for diagnostic clues like an abnormality in deep tendon reflexes, tonal abnormality and contractures, especially in those cases where promising result to initial treatment is unyielding on follow up visits like our case. Overtreatment with certain micronutrients like vitamin D often culminates in potentially hazardous adverse effects like confusion, apathy, recurrent vomiting, idiopathic intracranial hypertension, abdominal pain, polyuria, polydipsia, and dehydration [5].

\section{Compliance with Ethical Standards}

Conflict of Interest None.

\section{References}

1. Bönnemann CG. The collagen VI-related myopathies: Ullrich congenital muscular dystrophy and Bethlem myopathy. Handb Clin Neurol. 2011;101:81-96.

2. Panda PK, Sharawat IK. COL6A3 mutation associated early-onset isolated dystonia (DYT)-27: report of a new case and review of published literature. Brain Dev. 2020. https://doi.org/10.1016/j. braindev.2020.01.004.

3. McDonald L, Rennie A, Tolmie J, Galloway P, McWilliam R. Investigation of global developmental delay. Arch Dis Child. 2006;91:701-5.

4. Sharawat IK, Dawman L. Bone mineral density and its correlation with vitamin D status in healthy school-going children of Western India. Arch Osteoporos. 2019;14:13.

5. Sharawat IK. Hypervitaminosis D with dyslipidemia: an unusual scenario. Indian Pediatr. 2016;53:174-5.

Publisher's Note Springer Nature remains neutral with regard to jurisdictional claims in published maps and institutional affiliations. 